\title{
A FORMAÇÃO DO PEDAGOGO E A EDUCAÇÃO NAS PRISÕES: REFLEXÕES ACERCA DE UMA EXPERIÊNCIA
}

\author{
Marieta Gouvêa de Oliveira Penna ${ }^{1}$ \\ Alexandre Filordi de Carvalho ${ }^{1}$ \\ Luiz Carlos Novaes ${ }^{l}$
}

RESUMO: O objetivo deste artigo foi problematizar a formação do educador para atuar no novo contexto das Diretrizes Curriculares Nacionais, tendo como referência as diretrizes que orientam e organizam o curso de Pedagogia e a oferta da educação de jovens e adultos (EJA) nas escolas regulares e nos estabelecimentos penais. Para tanto, a partir de pesquisas sobre a temática, realizou-se um debate teórico-crítico em torno dos limites e das possibilidades implicados no exercício da docência em estabelecimentos penitenciários, bem como das condiçóes de contratação de professores, no estado de São Paulo, para este tipo de atuação docente. A formação do pedagogo, numa perspectiva crítica, foi abordada desde a experiência inovadora realizada na Universidade Federal de São Paulo.

Palavras-chave: Educação nas prisōes. Educação de jovens e adultos. Formação do pedagogo. Exercício da docência. Política educacional.

\footnotetext{
${ }^{1}$ Universidade Federal de São Paulo - São Paulo (SP), Brasil.

E-mail: marieta.penna@unifesp.br; filordi.carvalho@unifesp.br; luiz.novaes@unifesp.br Fonte de financiamento: Conselho Nacional de Desenvolvimento Científico e Tecnológico (CNPq).

DOI: 10.1590/CC0101-32622016162564
} 


\title{
Pedagogue training and education in prisons: reflections about an experience
}

\begin{abstract}
The aim of this paper was to problematize teacher education in order to act in the new context stablished by the Brazilian National Curriculum Guidelines, using as reference the guidelines that guide and organize the Pedagogy courses and the offers of adult education in mainstream schools and prisons. In order to do so, based on research on that subject, the article brings out a theoretical and critical debate around the limits and possibilities involved in teaching at prisons, as well as the recruitment conditions of those teachers in the state of Sáo Paulo, Brazil. The pedagogical training in a critical perspective was approached from the innovative experiment conducted at the Federal University of Sáo Paulo.
\end{abstract}

Keywords: Education in prisons. Adult education. Pedagogue training. Teaching practice. Educational policy.

\section{INTRODUÇÃO}

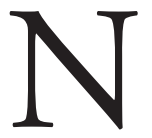

o texto das Diretrizes Curriculares Nacionais para o curso de graduação em Pedagogia (BRASIL, 2006), está prevista a formação de profissionais para atuarem na educação básica (com alunos de zero a dez anos) e na gestão de estabelecimentos educacionais, dedicados aos diferentes níveis e modalidades de ensino (educação de jovens e adultos - EJA, educação especial, ensino médio nas modalidades profissional e normal), abrangendo, inclusive, a educação diferenciada (escola do campo, educação indígena, educação quilombola). Trata-se de um amplo processo de formação, com vistas a oferecer ao futuro pedagogo condiçóes de estabelecer sólidas articulaçóes entre teoria e prática, em campos atravessados por disputas políticas e por debates acirrados sobre, de um lado, o que é necessário ensinar e, de outro, as consequências acerca do que se pode aprender com as experiências de ensino.

A educação nas prisóes, conforme as diretrizes nacionais para a oferta de educação para jovens e adultos em situação de privação de liberdade nos estabelecimentos penais (BRASIL, 2010), deve ser com- 
preendida na modalidade de EJA; apesar disso, tal faceta nem sempre é valorizada quando se trata da formação de pedagogos.

O texto pretende problematizar justamente a necessidade de os cursos de Pedagogia se atentarem para a referida temática, uma vez que é demanda urgente se pensar na formaçáo de um educador capaz de atuar com jovens e adultos em situação de privação de liberdade, seja no exercício da docência, da gestão ou da pesquisa. Para tanto, serão consideradas as experiências inovadoras junto ao curso de Pedagogia da Universidade Federal de São Paulo (Unifesp). Em tais situaçóes, por intermédio da unidade curricular denominada "Prática Pedagógica Programada: Educação Escolar nas Prisóes", realizaram-se, como fruto de pesquisas, debates e palestras com relação à temática, suscitando reflexões sobre a educação nas prisóes e a formação de professores. Dessa maneira, produziu-se um espaço importante de formação dos pedagogos, que antes tinha algumas lacunas.

Muito menos que uma proposta fechada, trata-se de compartilhar tal experiência com o intuito de potencializar o seu sentido e instigar aos pesquisadores e docentes envolvidos nos cursos de formação de professores a tomarem por desafio esse campo quase sempre ignorado na formação do educador. Assim, num primeiro momento, apresenta-se um percurso sobre a especificidade da educação escolar nas prisóes e do trabalho do professor nesse contexto, a partir do levantamento de pesquisas sobre a temática. Em seguida, vem a lume a partilha da situação deflagrada no curso de Pedagogia da Unifesp, visando à formaçáo do docente para a educação escolar nas prisóes.

\section{EXERCÍCIO DA DOCÊNCIA NA PRISÃO: ALGUNS APONTAMENTOS}

De acordo com Foucault (1977), a prisão no mundo moderno possui uma dupla finalidade, ou seja, punir e reabilitar para o convívio social indivíduos colocados sob sua guarda. Em suas palavras, trata-se de "[...] uma empresa de modificação dos indivíduos que a privação de liberdade permite fazer funcionar no sistema legal" (FOUCAULT, 1977, p. 209). O indivíduo preso, ao cumprir a pena que lhe foi atribuída, hipoteticamente, paga uma dívida à sociedade, além do fato de, supos- 
tamente, ser reabilitado para o convívio social. As dificuldades da prisão em cumprir o que preconiza em termos de reabilitação penal são evidentes; nas palavras de Foucault (1977, p. 208), “[...] conhecem-se todos os inconvenientes da prisão, e sabe-se que é perigosa quando não inútil”. Para Thompson (1976), a instituição prisional fracassa em seu objetivo de promover a ressocialização, que é incompatível com a punição e a disciplina, objetivos principais da prisão. Por isso, a tarefa de transformar criminosos em não criminosos não pode ser executada.

Refletir sobre a reabilitação não é uma tarefa fácil. $\mathrm{O}$ conceito indica a ideia de o indivíduo ter perdido a habilidade para o convívio social, ou mesmo de não a ter tido, e ser possível traçar estratégias para que volte ou passe a adquiri-la. Em uma sociedade cada vez mais desigual como a contemporânea, em que as relaçôes sociais são pautadas por relaçôes de poder que se endurecem até a dominação, como pode ser notado na dominação econômica, torna-se difícil pensar em homens reformando moralmente outros homens.

Ademais, a dinâmica prisional, tal como analisado por Goffman (1999), estabelece procedimentos que visam à anulação do sujeito, o qual deve se submeter às ordens e aos comandos da equipe dirigente. Nesse sentido, uma série de estratégias ao seu rebaixamento é desencadeada desde a sua chegada à instituição até a sua saída, com o objetivo de promover sua adequação às regras e normas da casa. Como parte dessas estratégias, têm-se a adoção de uniformes, o corte de cabelo e a substituição do nome por apelidos ou números de matrícula.

Desse modo, a educação escolar nas prisóes, prevista na Lei de Execução Penal como um direito (BRASIL, 1984), ao ser investigada, revela-se como espaço de contradiçóes, pois, ao mesmo tempo em que se encontra enredada nas malhas da instituição prisional, desponta como um espaço de possibilidades. Esse aspecto é evidenciado por Nassif (2006), que, ao examinar as práticas de disciplinamento dos detentos levadas a cabo na escola dentro da prisão, percebeu que elas conduzem a açóes e comportamentos diferenciados em relação aos demais espaços prisionais.

Estudos realizados sobre a escola na prisão, ao identificarem o significado que lhe é atribuído pelos detentos, auxiliam na compreensão do papel da escolarização nesse contexto. Como afirma Santos (2002), as marcas institucionais da escola são fortes e evidentes na instituição em fun- 
cionamento na prisão. Tais pesquisas demonstram que, para os presos, a escola representa acesso a aprendizagens escolares, tais como aprender a ler, a fazer contas, ampliar os conhecimentos e promover a certificação. A escola também tem marcas da instituição prisional e, nesse aspecto, é vista pelos detentos como espaço que ajuda a passar o tempo, a circular pela prisão, a estabelecer contato com detentos de outros pavilhóes ou mesmo na obtenção da análise de conduta favorável junto ao corpo técnico que compóe a equipe funcional (SANTOS, 2002; PORTUGUES, 2001). Cabe ressaltar que Goifman (1998), em seu estudo, obteve junto aos presos a percepção de que o tempo ocupado na escola tem uma qualidade a mais do que aquele período gasto em outras atividades possíveis de serem realizadas na prisão. Evidencia-se que na prisão, em que as escolhas são de fato reduzidas, a escola desponta como um valor (ONOFRE, 2002).

Os estudos relatam que a escola na prisão está submetida às dinâmicas carcerárias, mas que, ainda assim, é identificada e reconhecida como um local diferenciado, é de alguma forma separada do restante da cadeia, em que as relaçóes são distendidas e podem ser estabelecidas em outras bases. Náo se pode esquecer, como destacado, que o cumprimento da pena de privação de liberdade pressupôe a aniquilação das possibilidades afirmativas de liberdade do sujeito, contradizendo muito do que é regido pela escola. No entanto, brechas existem e, nesse sentido, torna-se relevante o estabelecimento de reflexóes sobre as necessidades formativas para aqueles que lecionam no ambiente prisional. É nessa direção, aliás, que são apresentadas pesquisas referentes à prática docente em estabelecimentos penitenciários, com o objetivo de fornecer subsídios para se refletir a formação de professores.

Um dos aspectos que se sobressaem nesses estudos é a necessidade de se atentar, ao considerar a prática docente nas prisóes, às especificidades nela implicadas, no que se refere à organização dos trabalhos escolares. Portanto, Hora e Gomes (2007) chamam a atenção para o fato de a escola na prisão estar condicionada a dispositivos disciplinares específicos, referidos à manutenção da ordem na instituição penitenciária. Por isso, entendem que as práticas docentes necessitam se amparar em procedimentos distintos, os quais levem em conta os tempos e espaços prisionais. Precisam considerar, por exemplo, a alta rotatividade dos alunos, o horário de tranca das celas, a dificuldade de circulação dos alunos pelo presídio, entre outros. 
Dentre os desafios enfrentados pelos professores ao lecionarem na prisão, Vieira (2008) destaca a constante imprevisibilidade, além das suas precárias condiçóes de trabalho. Abreu (2008), em seu estudo, se referiu ao fato de a formação recebida pelos professores não atender à especificidade do trabalho realizado, além da falta de material e de apoio institucional para as atividades desenvolvidas em sala de aula.

Paiva (2007) ponderou sobre a importância de se levar em conta a especificidade do alunado, duplamente discriminado, por não ter concluído a escolarização no tempo adequado e por sua condição de detento. Nesse contexto, de acordo com Julião (2007), as práticas pedagógicas precisam pautar-se pelos princípios da EJA, inserindo-se em um projeto pedagógico institucional que se articule em torno de preceitos implicados nessa modalidade de ensino. Ao analisar o currículo e as práticas pedagógicas efetivadas em escolas situadas em presídios no estado do Paraná, Queluz (2006) apontou a importância de se levarem a cabo ações baseadas pelos princípios da EJA e centradas na temática do trabalho. Na mesma direção, Silva (2004), Hora e Gomes (2007) também discutiram a importância de serem adotados princípios e concepçóes da EJA nas escolas das prisóes, respeitando-se os saberes acumulados pelos alunos ao longo da vida, o que também é enfatizado no texto das Diretrizes Nacionais para a educação nas prisões (BRASIL, 2010).

Partindo desse entendimento, evidencia-se a relevância do desenvolvimento de práticas pedagógicas que tenham como objetivo a promoção dos sujeitos, estimulando a reflexão e a participação dos alunos, desde a elaboração de programas educativos que respondam às suas necessidades (TEIXEIRA, 2007).

Ao analisar as contradiçóes presentes na escola dentro da prisão, cujas ações são estabelecidas em contexto de extrema opressão, Fiori (2003) ressaltou a importância da realização de práticas pedagógicas diferenciadas que levem em consideração essas contradiçóes. Logo, para além da oferta de escolarizaçáo e certificação, do ensino da leitura e escrita, trata-se de traçarem esforços para a efetivação de práticas que potencializem a reflexão e promovam a valorização dos alunos, o que por certo é tarefa difícil de efetivar, que demanda uma adequada formação dos professores.

A realização de objetivos educacionais na escola dentro da prisão exige dos professores que reflitam sobre o papel que lhes cabe desempenhar sobre a clareza do local em que atuam e os limites e as 
possibilidades da educação escolar nesse contexto. Os professores devem passar por uma formação que abarque questóes sobre o cotidiano prisional, a EJA, bem como aquelas relacionadas às possibilidades formativas em sociedade pautada por relaçóes de poder e dominação.

\section{A FORMAÇÃO DOS PROFESSORES E A DOCÊNCIA EM ESCOLAS NA PRISÃO: RELATO DE EXPERIÊNCIA}

A promulgação da Resolução CEB/CNE 2, de 25 de outubro de 2010, que instituiu as diretrizes nacionais para a oferta da educação para jovens e adultos em situação de privação de liberdade nos estabelecimentos penais, transferiu para as secretarias de educação a responsabilidade pela educação escolar no âmbito do sistema prisional. Dessa maneira, colocou-se em pauta a necessidade de se pensar na formação dos professores, dadas as especificidades que envolvem o trabalho com jovens e adultos em estabelecimentos penais. Trata-se, na verdade, do enfrentamento de uma dupla questão: por um lado, a educação de jovens e adultos e, por outro, a organização da atividade de ensino em um ambiente diferente da escola, tal como estamos habituados a considerar.

São poucos os cursos de formação de professores, entre eles o de Pedagogia, que trazem em seu currículo disciplinas ou atividades voltadas à EJA. Ao ignorar as especificidades que envolvem a EJA, a atençáo a esta população é negligenciada no processo de formação, restringindo-a, geralmente, às ofertas irregular e esporádica de disciplinas que se organizam em torno de tal enfoque. Se a discussão acerca da EJA, amplamente debatida na produção acadêmica, ainda encontra resistência no sentido de integrar os currículos dos cursos de formação docente, o que dizer da educação escolar realizada em ambientes não escolares, como é o caso dos estabelecimentos penais?

Considerando que a formação inicial docente não se revela suficiente para o enfrentamento das especificidades que marcam a educação escolar no interior dos estabelecimentos penais, a Escola de Filosofia, Letras e Ciências Humanas da Unifesp realiza, desde 2007, uma inovadora experiência de formação.

Durante os dois primeiros anos da formação do pedagogo, integra o currículo uma unidade curricular denominada 'práticas pedagógicas 
programadas' (PPP), que foi desenvolvida com o intuito de proporcionar ao profissional um espaço de aprendizagem que leve em consideração a diversidade de trajetórias profissionais, uma vez que processos educativos planejados também ocorrem em espaços não escolares. Além disso, buscou-se com a referida unidade curricular proporcionar aos alunos elementos concretos para a reflexão sobre o fenômeno educacional na sua complexidade. Esta perspectiva se difere do estágio supervisionado obrigatório, em que o foco é a educação escolar e o aluno deve acompanhar as práticas de profissionais habilitados em docência, coordenação pedagógica, orientação educacional e direção escolar no âmbito das unidades escolares, bem como a supervisão e a gestão do sistema de ensino. Organizadas a partir de grupos de, no máximo, dez alunos e sob a orientação de professores do curso, as PPP têm um repertório plural, com diferentes possibilidades de escolhas por parte dos estudantes, cujas atividades teóricas e práticas integram-se em torno de uma questão que problematiza a discussão ao longo do semestre.

Dentre as temáticas tratadas nas PPP, um grupo de professores vem trabalhando, desde 2008, com a "educação em locais de privação de liberdade". Inicialmente, as atividades com os alunos do curso de Pedagogia trataram do processo educativo que ocorria na Fundação Centro de Atendimento Socioeducativo ao Adolescente (Fundação Casa), instituição do Governo do Estado de São Paulo e vinculada à Secretaria de Estado da Justiça e da Defesa da Cidadania. A princípio, interessavam-se o acompanhamento e a discussão de como as aulas eram organizadas, tendo em vista a vinculação desta Fundação às escolas da rede estadual paulista, bem como a atuação da própria Fundação Casa neste processo. Posteriormente, a atenção do grupo de professores e alunos voltou-se à educação escolar realizada no âmbito do sistema prisional e, a partir de 2009, antes mesmo da promulgação da Resolução $\mathrm{CEB} / \mathrm{CNE} 2$, o grupo se reorganizou para acompanhar e investigar a educação escolar em curso nos presídios paulistas.

O trabalho realizado nesta unidade curricular, desenvolvida ao longo dos quatro primeiros semestres do curso de Pedagogia, compreendeu aproximadamente 30 alunos por semestre. Tal aspecto merece ser notado por uma dupla razão. De um lado, evidencia-se uma demanda represada em torno da formação dos educadores. $\mathrm{O}$ número de alunos matriculados nesta PPP excedeu, em muito, a média contemplada nas demais práticas pedagógicas. Com isso, de outro lado, observa-se que demanda há em torno do tema da educação prisional, o que, por si só, confere validade ao argumento 
de que é urgente que os cursos de formação de professores convoquem uma mobilização própria na direção desse horizonte formativo.

No caso específico desta PPP, os docentes responsáveis por ela empenharam-se em desenvolver, junto aos alunos, leituras variadas acerca da temática "educação no presídio", bem como de autores que problematizam questóes educacionais relacionadas às experiências e tentativas de ressocializaçáo de jovens e adultos presos, além da visita a um presídio paulista para observaçáo do trabalho desenvolvido pela escola ali existente e de entrevistas com monitores presos.

Após o retorno da visita ao presídio, no qual as alunas tiveram a oportunidade de acompanhar a um festival de poesias, com poemas escritos pelos presos e avaliados por uma comissão julgadora, além de poderem visitar uma feira de ciências, assim expressou-se uma das estudantes:

É impressionante como a gente até esquece que está dentro de um presídio, e de uma escola do presídio! Tudo é igualzinho na escola: as salas de aula, as lousas, as carteiras. A feira de ciências até parecia à da escola que frequentei: as maquetes, os cartazes, coisas de artesanato e eles [os presos] ali, explicando tudo, como se tivesse valendo nota. O festival de poesias, com poemas escritos pelos detentos, falando do seu dia a dia, de sua rotina e dos desejos de uma vida melhor. A gente só se dá conta de que está no presídio por causa dos guardas, da segurança e dos uniformes dos presos. Fiquei muito curiosa para entender como é o dia a dia deles na escola, de como o professor prepara aula, o que ele ensina para as pessoas que chegam ali com níveis diferentes de escolaridade, dos materiais que utiliza, da avaliação, enfim, de tudo aquilo que estava ali. Também fiquei pensando nas leituras de Paulo Freire, Foucault e do Adorno que fizemos na faculdade [PPP] e qual deveria ser para os presos o sentido desta educação na prisão. (Extraído do relato de uma aluna sobre a visita a um presídio paulista em 2012, durante a realizaçáo da PPP)

As impressões de tal aluna, também compartilhadas no relato das demais que visitaram o presídio, evidenciam que as discussóes realizadas no âmbito da PPP possibilitaram que as estudantes olhassem para a "escola do presídio" de um modo singular, pois, reconhecendo a 
especificidade do trabalho realizado ali, em condiçóes diferentes daquelas a que estavam habitualmente acostumadas, estranhavam a persistência da forma escolar em uma instituição que não era a escola. Ademais, conseguiram refletir sobre questóes relacionadas ao processo educativo, como a seleçấo de conteúdo; a metodologia de ensino; a avaliação e o sentido daquela experiência de educação escolar para os presos.

Essa experiência de formação inicial tem se mostrado bastante interessante no sentido de despertar nos futuros pedagogos a percepção sobre a importância em se pensar na docência em ambientes não escolares. Nesta experiência, ainda em andamento, tratar das especificidades da educação escolar realizada no âmbito da prisão tem levado os estudantes a refletirem de maneira mais abrangente sobre o sentido da educação escolar, dos seus modos e de suas formas de realização.

Apesar de julgarmos ser uma experiência bem-sucedida de formação, não podemos deixar de considerar que uma formação inicial adequada para o exercício docente em condiçóes tấo diversas - e em alguns casos, adversas - não é uma tarefa fácil. A transferência de responsabilidade pela educação nas prisóes às secretarias estaduais de educação desencadeou açóes de formação em serviço para dar conta de problemas relacionados ao treinamento inicial, bem como das especificidades que envolvem o trabalho docente no ambiente prisional.

Alguns estados brasileiros investem em treinamento, por meio de videoconferências ou parcerias com universidades. O Paraná, por exemplo, oferece aos professores que atuam no sistema prisional cursos ministrados pela Escola de Educação em Direitos Humanos do Paraná (ESEDH) e pela Secretaria de Estado da Educaçáo (SEED/PR), por meio de palestras, grupos de estudos, seminários e cursos de curta ou longa duração. Em Santa Catarina, cabe à secretaria de educação realizar cursos de "Educação em Prisóes”, com palestras, aulas expositivas, leitura de textos, debates, estudos de grupo e oficinas pedagógicas. No Ceará, que até 2010 não informava a presença de professores no sistema prisional, os docentes são selecionados e encaminhados a um curso de especialização, com vistas à atuação nos presídios. O estado de Mato Grosso prevê, em seu plano estadual de educação nas prisóes, que as açóes de formação continuada de docentes para atuação em prisões devem ser organizadas pela Coordenadoria de Educação de Jovens e Adultos, vinculada à Secretaria de Educação, e acompanhadas 
pelos formadores do Centro de Formação e Atualização dos Profissionais de Educação do Mato Grosso (CEFAPROS).

Não foi o intuito deste trabalho realizar um levantamento das ações desencadeadas em todas as secretarias de educação no Brasil acerca da formação continuada de professores para a atuação em estabelecimentos penais. No entanto, não podemos ignorar a importância deste tipo de ação diante das poucas iniciativas das universidades públicas e privadas, ainda não sensibilizadas para o importante papel de formar quadros para atuação em ambientes diversificados, como é o caso de presídios. Também não é demais lembrar que a ausência de políticas específicas e de planos de carreira e incentivos adequados, associados às condiçóes de trabalho, tem relegado a docência em estabelecimentos penais e em outras instituiçóes da privação de liberdade a jovens professores em início de carreira, muitos admitidos por meio de contratos temporários, para os quais tais ambientes são apresentados como a única alternativa possível de exercício profissional na esfera pública.

\section{CONSIDERAÇÕES FINAIS: ENTRE UMA EXPERIÊNCIA E VÁRIOS DESAFIOS}

\section{Termina-se tal reflexão com Foucault (1977):}

Nessa humanidade central e centralizada, efeito e instrumento de complexas relaçóes de poder, corpos e forças submetidos por múltiplos dispositivos de "encarceramento", objetos para discursos que são eles mesmos elementos dessa estratégia, temos que ouvir o ronco surdo da batalha. (p. 269)

Pode-se dizer que há um ronco surdo da batalha que se trava na formação dos professores no cenário político brasileiro atual. Em uma perspectiva, como estudado, há uma demanda instaurada por viés de consolidação política. Por mais que isso seja salutar e relevante, nem sempre os cursos formadores de professores esforçam-se para cumprir minimamente com as condiçóes necessárias dispostas entre empenho político e consolidação empírica da transformação política advinda pela ação. 
Com efeito, o caso da formação de professores para atuar na EJA em privação de liberdade desponta-se como atual. Ao que tudo indica, o dispositivo de encarceramento, tal como Foucault (1977) analisou, não diria respeito apenas aos intramuros prisionais, mas também às relaçóes de poder que se fecham frente aos desafios constantes que a educação, de um modo mais amplo, deveria ter, face aos próprios dispositivos que se consagram à manutenção das relaçóes de poder e dominação vigentes na sociedade atual.

Portanto, em primeiro lugar, compete a cada curso que forma professores questionar os modos pelos quais seus currículos se fecham às demandas pela formação de educadores para atuarem no sistema prisional. Além disso, cabe a eles indagar por que insistem em ignorar a real necessidade de fazer da especificidade da formação de professores um instrumento para a inserção transformadora em outros níveis institucionais da sociedade, como é o caso das prisóes e das casas correcionais de todo tipo. Como ficou demonstrado, há uma demanda reprimida que quase sempre é posta de lado ou tratada sem especificidade concretada. Nenhum tipo de alteração será realizado sem um mínimo de esforço e autoquestionamento de como os saberes são distribuídos, e com quais finalidades, nos cursos de formação de professores.

Mas há também, em segundo lugar, uma batalha que precisa ser considerada em seu aspecto político, ou mais precisamente, na dimensão de resistência que o próprio sistema prisional consolida, muitas vezes, ao fechar-se aos diálogos exógenos a ele. Em todos os anos de PPP, apenas por uma vez, depois de quase um ano de negociação, foi possível levar as alunas para visitar uma prisão. Esse centralismo deve ser revisto, afinal de contas, a formação instalada nas prisôes não deve privar nem a sociedade nem os presos de um mútuo diálogo. Afinal de contas, toda experiência com a educação pressupóe relaçóes dialógicas. Do ponto de vista da efetividade da política, pouco adianta instaurar uma demanda se o próprio sistema prisional não revê a sua maneira de conduzir as aproximaçóes entre possibilidades e experiências concretas de educação, e as finalidades aí pressupostas.

De todo modo, a questão da formação, quer seja a de pedagogos ou a de professores, para atuarem com a educação nas prisóes é uma demanda histórica incontornável. Ela exige uma constante problematização daquilo que temos feito de nós mesmos em nossa contemporanei- 
dade. O ronco surdo dessa batalha deve nos instigar ainda mais na busca de novas formas e experiências, com as quais seja possível pensar e agir diferentemente do que temos pensado e agido nesta e com esta temática.

\section{REFERÊNCIAS}

ABREU, A.A. Educação entre grades: um estudo sobre a educação penitenciária do Amapá. 2008. 130f. Dissertação (Mestrado em Educação) - Centro de Educação e Ciências Humanas, Universidade Federal de São Carlos, São Carlos, 2008.

BRASIL. Lei n. 7210, de 11 de julho de 1984. Lei de Execução Penal Brasileira. Diário Oficial da União, Brasília, DF, 13 jul. 1984. Seção I, p. 10227.

. Resolução CNE/CP n. 01, de 15 de maio de 2006. Institui as Diretrizes Curriculares Nacionais para o Curso de Graduação em Pedagogia Licenciatura. Diário Oficial da União, Brasília, DF, 16 maio 2006. Seção 1, p. 11.

. Resoluçáo CEB/CNE n. 2, de 25 de outubro de 2010. Diretrizes Nacionais para a oferta de educação para jovens e adultos em situaçáo de privação de liberdade nos estabelecimentos penais. Diário Oficial da União, Brasília, DF, 20 mai. 2010, Seção 1, p. 20.

FIORI, M.R. A educação na penitenciária feminina da capital: a crença da reabilitação. 2003. 131f. Dissertação (Mestrado em Educação, Administração e Comunicação) - Universidade São Marcos, São Paulo, 2003.

FOUCAULT, M. Vigiar e punir. Trad. Lígia M. P. Vassallo. Rio de Janeiro: Vozes, 1977.

GOFFMAN, E. Manicômios, prisóes e conventos. Trad. Dante Moreira Leite. 6. ed. São Paulo: Perspectiva, 1999.

GOIFMAN, K. Valetes em slow motion. Campinas: Unicamp, 1998.

HORA, D.M.; GOMES, P.R. Educação prisional: o problema do ponto de vista do currículo. Salto para o Futuro, Boletim 06 EJA e educação prisional. Brasília: MEC/SECAD, p. 34-43, 2007.

JULIĀO, E.F. Proposta pedagógica EJA e educação prisional educação para jovens e adultos privados de liberdade: desafios para a política de reinserção social. Salto para o Futuro, Boletim 06 EJA e educação prisional. Brasília: MEC/ SECAD, p. 3-13, 2007. 
NASSIF, N.N.N. Educação entre as grades: o espaço escolar na prisão e o disciplinamento dos apenados. 2006. 112f. Dissertação (Mestrado em Educação) - Universidade Luterana do Brasil, Canoas, 2006.

ONOFRE, E.M.C. Educação escolar na prisão. Para além das grades: a essência da escola e a possibilidade de resgate da identidade do homem aprisionado. 2002. 246f. Tese (Doutorado em Educação) - Faculdade de Ciências e Letras, Universidade Estadual Paulista, Araraquara, 2002.

PAIVA, J. Conteúdos e metodologia: a prática docente no cárcere. Salto para o Futuro, Boletim 06 EJA e educação prisional. Brasília: MEC/SECAD, p. 43-53, 2007.

PORTUGUES, M.R. Educação de adultos presos: possibilidades e contradições da inserção da educação escolar nos programas de reabilitação do Sistema Penal do Estado de São Paulo. 2001. 187f. Dissertação (Mestrado em Educação) Faculdade de Educação, Universidade de São Paulo, São Paulo, 2001.

QUELUZ, E.L. Cela de aula: espaço de ensino-aprendizagem. 2006. $127 f$. Dissertação (Mestrado em Educação) - Universidade Federal do Paraná, Curitiba, 2006.

SANTOS, S. A educação escolar no sistema prisional sob a ótica dos detentos. 2002. 148f. Dissertação (Mestrado em Educação) - Pontifícia Universidade Católica de São Paulo, São Paulo, 2002.

SILVA, M.C.V. A prática docente da EJA: o caso da Penitenciária Juiz Plácido de Souza em Caruaru. 2004. 247f. Dissertação (Mestrado em Educação) - Centro de Educação, Universidade Federal de Pernambuco, Recife, 2004.

TEIXEIRA, C.J.P. O papel da educação como programa de reinserção social para jovens e adultos privados de liberdade: perspectivas e avanços. Salto para o Futuro, Boletim 06 EJA e educação prisional. Brasília: MEC/SECAD, p. 14-21, 2007.

THOMPSON, A.F.G. A questão penitenciária. Petrópolis: Vozes, 1976.

VIEIRA, E.L.G. Trabalho docente: de portas abertas para o cotidiano de uma escola prisional. 2008. 137f. Dissertação (Mestrado em Educação) - Pontifícia Universidade Católica do Rio de Janeiro, Rio de Janeiro, 2008.

Recebido em 11 de setembro de 2015.

Aceito em 22 de fevereiro de 2016. 